AGRITECH, Vol. 37, No. 1, Februari 2017, Hal. 59-68 DOI: http://dx.doi.org/10.22146/agritech.17011 ISSN 0216-0455 (Print), ISSN 2527-3825 (Online) Tersedia online di https://jurnal.ugm.ac.id/agritech/

\title{
Karakterisasi Kemasan Kertas Aktif dengan Penambahan Oleoresin Ampas Destilasi Sereh Dapur (Cymbopogon citratus)
}

\author{
Characterization of Active Paper Packaging with Addition of Distillation Dregs Oleoresin of Lemongrass \\ (Cymbopogon citratus)
}

\section{Lia Umi Khasanah, Windi Atmaka, Dewi Kurniasari, K. Kawiji, Danar Praseptiangga, Rohula Utami}

\author{
Jurusan Teknologi Hasil Pertanian, Fakultas Pertanian, Universitas Sebelas Maret \\ J1. Ir. Sutami 36 A, Kentingan, Surakarta 57126, Indonesia \\ Email: liaumikhasanah@yahoo.co.id
}

Submisi: 5 Agustus 2015; Penerimaan: 30 Maret 2016

\begin{abstract}
ABSTRAK
Tujuan dari penelitian ini adalah untuk mengetahui pengaruh konsentrasi oleoresin ampas destilasi sereh dapur $(0 \%, 2 \%, 4 \%$, dan $6 \%$ b/b) terhadap karakteristik kemasan kertas aktif (analisis sensoris, kadar air, ketebalan, ketahanan tarik, ketahanan lipat, dan aktifitas antimikroba), mengetahui gugus fungsi kemasan kertas aktif kontrol dan konsentrasi oleoresin ampas destilasi sereh dapur terpilih, mengetahui pengaruh waktu penyimpanan $(0,5,10$, 15, dan 20 hari) terhadap karakteristik kemasan kertas aktif kontrol dan konsentrasi oleoresin ampas destilasi sereh dapur terpilih (uji ketahanan lipat dan ketahanan tarik), dan mengetahui aktivitas antimikroba kemasan kertas aktif kontrol dan konsentrasi oleoresin ampas destilasi sereh dapur terpilih sebelum dan setelah penyimpanan selama 20 hari. Hasil penelitian menunjukkan bahwa konsentrasi oleoresin berpengaruh nyata terhadap warna, overall (penerimaan keseluruhan), ketahanan tarik, ketahanan lipat, dan aktivitas antimikroba tetapi berpengaruh tidak nyata terhadap aroma, tekstur, kadar air, dan ketebalan kemasan kertas aktif. Penambahan oleoresin ampas destilasi sereh dapur meningkatkan kadar air, ketebalan, dan aktivitas antimikroba serta menurunkan ketahanan tarik, ketahanan lipat, dan penerimaan panelis. Kemasan kertas aktif mengandung gugus fungsi selulosa, kitosan, dan tween 80 serta pada kemasan kertas aktif penambahan oleoresin konsentrasi $2 \%$ terdapat gugus fungsi oleoresin sereh dapur. Waktu penyimpanan tidak berpengaruh secara nyata terhadap ketahanan tarik dan ketahanan lipat kemasan kertas aktif kontrol dan konsentrasi terpilih. Kemasan kertas aktif kontrol dengan kemasan kertas aktif penambahan oleoresin konsentrasi $2 \%$ berbeda nyata di setiap 5 hari penyimpanan. Namun, penyimpanan selama 20 hari tidak berpengaruh secara nyata terhadap aktivitas antimikroba kemasan kertas aktif kontrol dan konsentrasi terpilih.
\end{abstract}

Kata kunci: Kemasan kertas aktif; ampas; sereh dapur; oleoresin

\begin{abstract}
The aims of this research were to determine the effect of lemongrass distillation dregs oleoresin concentration $(0$ $\%, 2 \%, 4 \%$, and $6 \% \mathrm{~b} / \mathrm{b}$ ) on the active paper packaging characteristics (sensory, water content, thickness, tensile strength, fold endurance and antimicrobial activity), to determine the functional groups of the control and selected active paper packaging, to determine the effect of days of storage $(0,5,10,15$, and 20 day) on the control and selected active paper packaging characteristics (tensile strength, and fold endurance), and to determine antimicrobial activity of the control and selected active paper packaging during 20 days storage. The result showed that the concentration of lemongrass distillation dregs oleoresin significantly affected the color, overall, tensile strength, fold endurance, and antimicrobial activity while did not significantly affected the flavor, texture, water content, and thickness of the
\end{abstract}


active paper packaging. The addition of lemongrass distillation dregs oleoresin increased the water content, thickness, microbial activity, while decreased the panelists preference, tensile strength and fold endurance of the active paper packaging. The spectrum of functional groups of the active paper packaging showed the presence of chitosan, cellulose, tween 80 , and lemongrass oleoresin. The storage days had no significant effect on tensile strength and fold endurance of the control and selected active paper packaging. The control and selected active paper packaging were significantly different at each 5 days storage. However the 20 day of storage showed no significant effect on the antimicrobial activity of the control and selected active paper packaging.

Keywords: Active paper packaging, dregs; lemongrass; oleoresin

\section{PENDAHULUAN}

Kemasan memegang peranan penting dalam pengawetan produk pangan. Kemasan dapat mencegah kerusakan produk pangan, melindungi bahan pangan yang dikemas dari bahaya pencemaran dan gangguan fisik seperti gesekan, benturan, dan getaran. Di samping itu kemasan juga berfungsi untuk memudahkan dalam proses penyimpanan, pengangkutan, dan pendistribusian serta sebagai daya tarik pembeli (Fauzi, 2006).

Kemasan dapat dikembangkan menjadi kemasan aktif. Menurut Dobrucka dan Cierpiszewski (2014), kemasan aktif merupakan penggabungan senyawa aditif tertentu ke dalam film kemasan dengan tujuan untuk mempertahankan atau meningkatkan umur simpan produk. Suatu kemasan dapat dikatakan sebagai kemasan aktif ketika dapat menjalankan beberapa peran dalam pengawetan makanan dan memberikan penghalang inert untuk kondisi eksternal. Salah satu contoh kemasan aktif adalah kemasan kertas aktif. Kemasan kertas memiliki kelebihan yaitu harganya lebih murah, mudah didapat, dan penggunaannya lebih luas. Kemasan kertas aktif dapat menghambat pertumbuhan mikrobia pada buahbuahan, sayuran, dan daging. Kertas aktif yang terbuat dari kertas yang dilapisi parafin dan diinkorporasi minyak atsiri kayu manis sebanyak $2 \%, 4 \%$, dan $6 \%$ dapat menghambat pertumbuhan R. stolonifer (Rodriguez dkk., 2008).

Rempah-rempah telah banyak diteliti memiliki kandungan antimikroba dan antioksidan baik dalam minyak atsiri maupun oleoresin. Edible film dengan penambahan 0,1 $\%$ (v/v air) minyak atsiri kunyit putih mampu menghambat Pseudomonas putida dan Pseudomonas fluorescens (Utami dkk., 2013). Minyak atsiri sereh dapur mampu menghambat pertumbuhan jamur Aspergillus sp. pada konsentrasi minimum $0,3 \%$ dengan presentase daya hambat $23,92 \%$ dan pada konsentrasi 0,5\% dapat menghambat $100 \%$ (Ella dkk., 2013).

Sereh dapur (Cymbopogon citratus) merupakan jenis tanaman dari keluarga rumput-rumputan yang mempunyai aroma yang kuat dan wangi karena mengandung minyak atsiri (Kusumayadi dkk., 2013). Minyak atsiri sereh dapur hasil destilasi langsung selama 4 jam memiliki rendemen sebesar 0,303\% dan kadar sitral 76,3 \% (Kawiji dkk., 2010). Selain minyak atsiri, oleoresin juga dapat dihasilkan dari sereh dapur. Oleoresin merupakan campuran dari minyak atsiri dan resin (padatan) yang diperoleh dengan ekstraksi. Dibandingkan minyak atsiri, oleoresin memiliki aroma dan flavor yang lebih kuat dan sama dengan rempah segar. Kandungan oleoresin sereh dapur yang diperoleh menggunakan metode Pressuried Liquid Extraction (PLE) dengan pelarut etanol adalah neral dan geranial berturut-turut sebanyak $6,23 \pm 0,7$ dan 17,06 \pm $0,7 \mathrm{mg} / 100 \mathrm{~g}$ sereh dapur (Ain dkk., 2013).

Menurut Harris (1993) produksi minyak sereh dapur di Indonesia tidak tetap dengan ekspor berkisar antara 2-3 ton minyak/tahun. Rendemen minyak atsiri sereh dapur $0,3-0,5$ $\%$, maka ampas destilasi sereh dapur yang dihasilkan per tahun di Indonesia berkisar 400-1.000 ton. Pada destilasi sereh dapur hanya mendapatkan komponen volatil yaitu minyak atsiri sereh dapur sedangkan resin yang terkandung dalam sereh dapur belum terambil. Biasanya ampas hasil destilasi digunakan sebagai bahan bakar tungku penyulingan padahal dalam ampas tersebut masih terkandung oleoresin (Budi, 2009). Sehingga ampas destilasi sereh dapur dapat dimanfaatkan untuk menghasilkan oleoresin. Oleoresin yang dihasilkan tersebut dapat ditambahkan ke dalam kemasan kertas aktif sehingga dapat menunjang perannya sebagai kemasan antimikroba.

Oleh karena itu, perlu dilakukan penelitian untuk mengetahui konsentrasi oleoresin ampas destilasi sereh dapur yang ditambahkan ke dalam kemasan kertas aktif yang dapat menghambat pertumbuhan mikroba dan memiliki karakteristik fisik, kimia, serta sensori yang baik.

\section{METODE PENELITIAN}

\section{Alat dan Bahan}

Bahan yang digunakan adalah sereh dapur (Pasar Legi, Surakarta), etanol $96 \%$, kertas saring, kitosan, asam asetat, aquades, pati tapioka, tween $80, \mathrm{NaCl}, \mathrm{KBr}$, Pseudomonas flourescens FNCC 0071, Aspergillus niger FNCC 6018, Nutrient Agar, Potato Dextrose Agar, dan silica gel. Alat yang 
digunakan adalah hot plate, labu leher tiga, termometer, rotary vacuum evaporator IKA RV-10 Basic, blender "Cosmos", alat pencetak kertas ukuran 20 × $30 \mathrm{~cm}$, MIT Folding Endurance Tester, Tensile Tester - Kao Tieh (Model KT-7010-A2), IR spectrometer Nicolet Magna 4R/ Avatar-360, alat gelas, dan alat analisis.

\section{Tahapan Penelitian}

Ampas destilasi sereh dapur berasal dari limbah destilasi uap sereh dapur. Ampas destilasi sereh dapur dikeringanginkan selama 24 jam dan diekstraksi maserasi dengan pelarut etanol $96 \%$ pada perbandingan bahan dengan pelarut adalah 1:5 (b/v) (Danlami dkk., 2011). Ekstraksi dilakukan pada suhu $78^{\circ} \mathrm{C}$ selama 5 jam 14 menit (Khasanah dkk., 2013). Penyaringan dilakukan untuk memisahkan ampas dengan ekstrak. Pemisahan antara oleoresin dengan pelarut dilakukan menggunakan rotary evaporator $90 \mathrm{rpm}$ suhu $60^{\circ} \mathrm{C}$.

Pembuatan kertas aktif mengacu pada metode yang dikembangkan oleh Manuhara (2013) dan Hadi (2008). Potongan kertas saring (2 mm x $2 \mathrm{~mm}$ ) sebanyak $15 \mathrm{~g}$ direndam dalam $250 \mathrm{~mL}$ aquades selama 24 jam. Rendaman potongan kertas ditambah dengan $250 \mathrm{~mL}$ aquades dan dihancurkan dengan blender selama 5 menit hingga menjadi pulp. Pati tapioca $30 \%$ (b/b) dilarutkan ke dalam $50 \mathrm{~mL}$ aquades dan dicampur dengan pulp menggunakan blender selama 5 menit.

Bubuk kitosan sebanyak 0,45 g ditambahkan ke dalam gelas beker berisi $100 \mathrm{~mL}$ asam asetat $1 \%$ dan diaduk hingga terbentuk larutan kitosan dalam asam asetat. Larutan kitosan tersebut dicampur dengan blender selama 5 menit. Dalam tiga gelas beker lain yang telah terisi $50 \mathrm{~mL}$ aquades, masingmasing ditambahkan oleoresin ampas destilasi sereh dapur dengan konsentrasi $2 \%, 4 \%$, dan $6 \%$ (b/b) terhadap kertas saring, ditambahkan tween 80 dan dilakukan pengadukan menggunakan magnetic stirrer pada suhu ruang hingga terbentuk emulsi oleoresin ampas destilasi sereh dapur dalam aquades. Sedangkan konsentrasi $0 \%$ (tanpa penambahan oleoresin) tidak ditambahkan tween 80. Emulsi oleoresin dalam aquades diblender selama 5 menit.

Pencetakan dilakukan secara manual di atas alat pencetak kayu $20 \mathrm{~cm}$ x $30 \mathrm{~cm}$. Adonan kertas dituang ke permukaan saringan dalam alat pencetak hingga rata dan terbentuk lembaran kertas basah. Lembaran kertas basah di atas permukaan saringan ditekan di antara permukaan kaca dengan beban $2 \mathrm{~kg}$ selama 10 menit. Lembaran kertas basah dikeringkan pada suhu $30{ }^{\circ} \mathrm{C}$ selama 48 jam dengan diselingi pembalikan kertas setelah 24 jam pengeringan.

\section{Rancangan Penelitian}

Penelitian ini terdiri dari empat tahapan. Tahapan pertama untuk mengetahui pengaruh konsentrasi oleoresin ampas destilasi sereh dapur $(0 \%, 2 \%, 4 \%$, dan $6 \% \mathrm{~b} / \mathrm{b})$ terhadap karakteristik kemasan kertas aktif (analisis sensoris, kadar air, ketebalan, ketahanan tarik, dan ketahanan lipat, dan aktifitas antimikroba) (Table 1). Rancangan yang digunakan adalah Rancangan Acak Lengkap (RAL) dengan satu faktor. Data dianalisis menggunakan ANOVA dengan taraf signifikansi $5 \%$. Jika berpengaruh nyata dilanjutkan dengan Duncan Multiple Range Test (DMRT) dengan taraf siginifikansi yang sama. Tahapan kedua untuk mengetahui gugus fungsi kemasan kertas aktif kontrol dan konsentrasi oleoresin ampas destilasi sereh dapur terpilih. Tahapan ketiga untuk mengetahui pengaruh waktu penyimpanan $(0,5,10$, 15, dan 20 hari) terhadap karakteristik kemasan kertas aktif kontrol dan konsentrasi oleoresin ampas destilasi sereh dapur terpilih (uji ketahanan lipat dan ketahanan tarik). Rancangan percobaan tahapan ini menggunakan RAL. Data dianalisis menggunakan ANOVA dengan taraf signifikansi $5 \%$. Jika berpengaruh nyata dilanjutkan dengan (DMRT) dengan taraf siginifikansi yang sama. Sedangkan untuk mengetahui perbedaan karakteristik kemasan kertas aktif kontrol dan konsentrasi oleoresin ampas destilasi sereh dapur terpilih selama penyimpanan data dianalisis menggunakan t-test dengan taraf signifikansi $5 \%$. Tahapan keempat untuk mengetahui aktivitas antimikroba kemasan kertas aktif kontrol dan konsentrasi oleoresin ampas destilasi sereh dapur terpilih sebelum dan setelah penyimpanan selama 20 hari. Data yang dihasilkan dianalisis menggunakan t-test dengan taraf signifikansi $5 \%$.

\section{HASIL DAN PEMBAHASAN}

\section{Analisis Sensoris Kemasan Kertas Aktif}

Penambahan oleoresin berpengaruh tidak nyata terhadap penerimaan panelis pada parameter aroma dan tekstur tetapi berpengaruh nyata pada parameter warna dan overall (penerimaan keseluruhan). Pada parameter warna, konsentrasi $2 \%$ (b/b) memiliki warna yang lebih disukai dibandingkan konsentrasi $4 \%$ dan $6 \%$. Semakin tinggi konsentrasi oleoresin yang ditambahkan maka warna kertas semakin tidak disukai oleh panelis. Hal ini dikarenakan semakin tinggi konsentrasi oleoresin yang ditambahkan maka warna kertas semakin hijau sesuai dengan warna oleoresin, sedangkan panelis lebih menyukai kertas yang berwarna putih. Hal ini sesuai dengan hasil penelitian Sucipto dkk. (2009) tentang kertas dari pelepah pisang yang menunjukkan bahwa panelis lebih menyukai warna kertas yang cerah. 
Tabel 1. Hasil uji sensoris kemasan kertas aktif dengan penambahan oleoresin ampas destilasi sereh dapur

\begin{tabular}{ccccc}
\hline \multirow{2}{*}{ Kertas aktif } & \multicolumn{4}{c}{ Parameter } \\
\cline { 2 - 5 } & Warna & Aroma & Tekstur & Penerimaan keseluruhan \\
\hline Kontrol & $4,17^{\mathrm{c}} \pm 0,75$ & $3,40^{\mathrm{a}} \pm 0,62$ & $3,43^{\mathrm{a}} \pm 0,90$ & $3,83^{\mathrm{c}} \pm 0,83$ \\
Oleoresin 2 \% & $3,50^{\mathrm{b}} \pm 0,82$ & $3,43^{\mathrm{a}} \pm 0,50$ & $3,07^{\mathrm{a}} \pm 0,64$ & $3,43^{\mathrm{b}} \pm 0,57$ \\
Oleoresin 4 \% & $3,00^{\mathrm{a}} \pm 0,74$ & $3,30^{\mathrm{a}} \pm 0,54$ & $3,07^{\mathrm{a}} \pm 0,98$ & $3,17^{\mathrm{ab}} \pm 0,70$ \\
Oleoresin 6 \% & $2,87^{\mathrm{a}} \pm 0,90$ & $3,20^{\mathrm{a}} \pm 0,76$ & $3,07^{\mathrm{a}} \pm 0,83$ & $2,93^{\mathrm{a}} \pm 0,87$ \\
\hline
\end{tabular}

Keterangan:

Notasi huruf yang sama pada kolom yang sama menunjukkan tidak berbeda nyata pada taraf signifikansi $5 \%$

Nilai 1 = sangat tidak suka, $2=$ tidak suka, $3=$ netral, $4=$ suka, $5=$ sangat suka

\section{Karakteristik Fisik}

Penambahan oleoresin tidak berpengaruh terhadap kadar air kemasan kertas aktif (Tabel 2). Kadar air kertas aktif dipengaruhi oleh penambahan Tween 80 dalam bubur kertas. Menurut Prasetyo (2005), penambahan Tween 80 pada pembuatan kopi instan mempengaruhi penurunan kadar air. Tween 80 yang berfungsi sebagai emulsifier dapat memperbanyak terbentuknya busa serta menurunkan tegangan permukaan antara dua fasa, sehingga pengeringan lebih cepat dan akan menghasilkan kadar air yang lebih rendah dengan lama pengeringan yang sama. Namun, Tween 80 juga bersifat higroskopis yang berarti bisa menyerap air dari lingkungan. Menurut Kurniasih (2011), kitosan memiliki sifat higroskopis karena kemampuan gugus amina kitosan yang mampu mengikat air. Sifat higroskopis dari kitosan ini diduga yang membuat kadar air kertas aktif tinggi akibat air yang terikat oleh gugus amina tidak bisa teruapkan secara baik. Penambahan tapioka dalam pembuatan kertas aktif yang berfungsi sebagai perekat juga berpengaruh terhadap kadar air. Penambahan bahan aditif seperti tapioka dapat mengisi celah antar serat sehingga memperkecil kemungkinan masuknya air ke dalam celah tersebut (Syamsu dkk., 2012). Menurut SNI 0123:2008 tentang karton dupleks, kadar air maksimal yaitu $10 \%$ sehingga kadar air kemasan kertas aktif dengan berbagai penambahan konsentrasi oleoresin sudah sesuai dengan standar.
Penambahan oleoresin ampas destilasi sereh dapur tidak berpengaruh terhadap ketebalan kertas. Sejumlah penelitian menyebutkan bahwa semakin banyak bahan yang ditambahkan maka total padatan yang terkandung dalam kertas semakin tinggi sehingga ketebalan kertas semakin tinggi. Amaliya dan Putri (2014) melaporkan bahwa semakin tinggi konsentrasi pati jagung dan kunyit putih maka ketebalan edible film akan semakin meningkat. Tongnuanchan dkk. (2014) juga menyebutkan bahwa penambahan berbagai jenis minyak atsiri dapat meningkatkan ketebalan film. Menurut Schuur (1988), kemasan yang digunakan untuk distribusi buah umumnya adalah kotak kardus ber-flute dengan ketebalan 0,85-3 mm. Kardus ber-flute yaitu kardus yang bagian tengahnya bergelombang. Ketebalan kemasan kertas aktif pada penelitian ini sudah memenuhi standar kemasan untuk distribusi.

Penambahan oleoresin berpengaruh nyata terhadap ketahanan tarik kemasan kertas aktif. Semakin tinggi oleoresin yang ditambahkan maka ketahanan tarik kertas semakin turun. Hal ini sesuai dengan penelitian Tongnuanchan dkk. (2014) yang menyebutkan bahwa penambahan minyak atsiri dapat menurunkan ketahanan tarik film karena minyak atsiri mengandung molekul non polar yang tinggi sehingga dapat mengurangi kekompakan jaringan film. Ketahanan tarik film berbasis pati-alginat juga mengalami penurunan seiring dengan penambahan konsentrasi minyak atsiri sereh dapur

Tabel 2. Karakteristik fisik kemasan kertas aktif dengan penambahan oleoresin ampas destilasi sereh dapur

\begin{tabular}{ccccc}
\hline \multirow{2}{*}{ Kertas aktif } & \multicolumn{4}{c}{ Parameter } \\
\cline { 2 - 6 } & Kadar air (\%) & Ketebalan $(\mathrm{mm})$ & Ketahanan tarik (N/mm) & Ketahanan lipat \\
\hline Kontrol & $8,845^{\mathrm{a}} \pm 0,569$ & $8,540^{\mathrm{a}} \pm 0,226$ & $1,689^{\mathrm{b}} \pm 0,023$ & $1,010^{\mathrm{b}} \pm 0,042$ \\
Oleoresin 2\% & $8,996^{\mathrm{a}} \pm 0,720$ & $8,725^{\mathrm{a}} \pm 0,092$ & $0,723^{\mathrm{a}} \pm 0,070$ & $0,540^{\mathrm{a}} \pm 0,000$ \\
Oleoresin 4 \% & $8,375^{\mathrm{a}} \pm 0,228$ & $8,864^{\mathrm{a}} \pm 0,529$ & $0,624^{\mathrm{a}} \pm 0,103$ & $0,544^{\mathrm{a}} \pm 0,062$ \\
Oleoresin 6\% & $9,125^{\mathrm{a}} \pm 0,791$ & $9,125^{\mathrm{a}} \pm 0,120$ & $0,571^{\mathrm{a}} \pm 0,095$ & $0,571^{\mathrm{a}} \pm 0,044$ \\
\hline
\end{tabular}

Keterangan:

Notasi huruf yang sama pada kolom yang sama menunjukkan berbeda tidak nyata pada taraf signifikansi $5 \%$ 
(Maizura dkk., 2007). Menurut SNI 7273:2008 tentang Kertas Koran, ketahanan tarik minimal kertas adalah $1,18 \mathrm{kN} / \mathrm{m}$.

Penambahan oleoresin berpengaruh nyata terhadap ketahanan lipat kertas (Tabel 2). Pengaruh tersebut disebabkan oleh adanya tween 80 yang ditambahkan ke dalam kemasan kertas aktif dengan penambahan oleoresin $2 \%, 4 \%$, dan $6 \%$. Menurut Prasetyo dan Vincentius (2005), penambahan tween 80 berfungsi sebagai pembuat busa. Busa yang dihasilkan tersebut menyebabkan permukaan kertas berpori yang menyebabkan kertas mudah putus saat dilipat, sedangkan antara kemasan kertas aktif penambahan oleoresin $2 \%, 4 \%$, dan $6 \%$ berbeda tidak nyata karena jumlah tween 80 yang ditambahkan sama yaitu sebanyak tiga tetes. Berdasarkan Peraturan Kepala Arsip Nasional Republik Indonesi Nomor 30 tahun 2011 tentang Pedoman Penggunaan Kertas untuk Arsip/Dokumen Permanen, ketahanan lipat kertas arsip dengan menggunakan metode MIT adalah minimal 2,18 atau setara dengan 150 jumlah lipatan.

\section{Uji Antimikroba}

Hasil pengujian aktivitas antimikroba terhadap Psedomonas flourescens (Tabel 3) menunjukkan bahwa penambahan oleoresin ampas destilasi sereh dapur ke dalam kemasan kertas aktif berpengaruh nyata terhadap aktivitas antimikroba kertas aktif. Semakin tinggi konsentrasi oleoresin yang ditambahkan maka penghambatan terhadap bakteri Pseudomonas fluorescens semakin meningkat. Peningkatan aktivitas antimikroba dikarenakan dalam kertas aktif terdapat senyawa aktif dari oleoresin sereh dapur yaitu sitral. Menurut Utami dkk. (2013), ketika oleoresin ditambahkan ke dalam kemasan kertas aktif, senyawa aktif yang terkandung dalam oleoresin tersebut akan terdifusi ke media agar dan menghasilkan zona bening pada media pertumbuhan mikroba. Menurut Rahman dkk. (2013) minyak atsiri sereh dapur lebih efektif dalam menghambat bakteri gram positif yaitu Staphylococcus aureus dibandingkan dengan bakteri gram negatif yaitu Escherichia coli. Hal ini dikarenakan bakteri gram positif lebih sensitif terhadap senyawa antibakteri karena struktur dinding sel bakteri gram positif lebih sederhana sehingga memudahkan senyawa antibakteri masuk ke dalam sel gram positif. Sedangkan bakteri gram negatif memiliki dinding sel yang lebih kompleks.

Selain adanya senyawa aktif dari oleoresin, zona hambat kertas aktif juga disebabkan oleh adanya kitosan yang juga berperan sebagai agen antimikroba. Bakteri gram negatif dengan lipopolisakarida di lapisan luarnya memiliki kutup negatif yang sangat sensitif terhadap kitosan (Killay, 2013). Menurut Pebriani dkk. (2012), kitosan memiliki polikation bermuatan positif yang mampu menekan pertumbuhan bakteri dan kapang. Adapun mekanisme penghambatan mikroba oleh kitosan yaitu kitosan mempunyai gugus fungsional amina $\left(-\mathrm{NH}_{2}\right)$ yang bermuatan positif yang sangat reaktif, sehingga mampu berikatan dengan dinding sel bakteri yang bermuatan negatif. Ikatan ini terjadi pada situs elektronegatif di permukaan dinding sel bakteri. Oleh karena itu, kertas aktif kontrol memiliki aktivitas penghambatan terhadap Pseudomonas fluorescens karena adanya kitosan. Menurut Nurainy (2008), kitosan dapat berikatan dengan lipid yang ada pada permukaan dinding sel bakteri. Pengikatan tersebut mengakibatkan lipid pada dinding sel bakteri rusak sehingga pertahanan sel bakteri juga rusak. Hal ini lah yang menyebabkan kertas aktif kontrol menghasilkan zona bening.

Aktivitas antimikroba terhadap Aspergillus niger $\left(10^{3}\right.$ $\mathrm{sel} / \mathrm{mL}$ ) menunjukkan beda tidak nyata di semua perlakuan (Tabel 3). Menurut Elifah (2010), diameter zona hambat tidak selalu naik sebanding dengan naiknya konsentrasi antibakteri, kemungkinan ini terjadi karena perbedaan kecepatan difusi senyawa antibakteri pada media agar. Fitriani dkk. (2013) menyebutkan bahwa kecepatan difusi ekstrak ke dalam media agar dipengaruhi oleh kekentalan ekstrak. Ekstrak yang terlalu kental menyebabkan sukar berdifusi ke dalam medium agar dan masuk ke dalam dinding sel jamur sehingga mempengaruhi ukuran zona hambat yang terbentuk.

Menurut Matasyoh dkk. (2011), minyak atsiri sereh dapur memiliki kemampuan sebagai antijamur dengan adanya senyawa aktif neral dan geranial. Neral dan geranial merupakan isomer aldehida monoterpena asiklik dari sitral. Aktivitas antimikroba minyak sereh dapur sebanyak $11,8 \mu \mathrm{g}$ x $10^{2}$ dan $5,9 \mu \mathrm{g} \times 10^{2}$ memberikan penghambatan terhadap Aspegillus niger dengan zona bening sebesar berturut-turut yaitu 10,67 $\pm 0,58 \mathrm{~mm}$ dan 10,33 $\pm 0,58 \mathrm{~mm}$ (Matasyoh dkk., 2011).

Pada kertas aktif penambahan oleoresin $0 \%$ memiliki zona bening karena dalam kertas tersebut terdapat kitosan yang juga dapat berfungsi sebagai antikapang. Sifat kitosan sebagai antikapang disebabkan oleh interaksi gugus aktif dari kitosan $\left(-\mathrm{NH}_{2}^{+}\right)$dengan lipid di plasma membran yang menyebabkan perubahan morfologi dan gangguan permukaan sel kapang (Chasanah, 2013).

Berdasarkan uji antimikroba, kemasan kertas aktif penambahan oleoresin konsentrasi $0 \%, 2 \%, 4 \%$, dan $6 \%$ memiliki daya hambat sedang terhadap bakteri Pseudomonas fluorescens dan memiliki daya hambat kuat terhadap jamur Aspergillus niger. Davis dan Stout (1971) menyatakan bahwa ketentuan kekuatan antibakteri sebagai berikut: daerah zona bening $20 \mathrm{~mm}$ atau lebih termasuk sangat kuat, daerah zona bening 10-20 mm termasuk kategori kuat, daerah zona bening 5-10 $\mathrm{mm}$ termasuk kategori sedang, dan daerah zona bening kurang dari sama dengan $5 \mathrm{~mm}$ termasuk kategori lemah. 
Tabel 3. Hasil pengujian aktivitas antimikroba

\begin{tabular}{ccc}
\hline \multirow{2}{*}{ Kertas aktif } & \multicolumn{2}{c}{ Diameter zona bening $(\mathrm{mm})$} \\
\cline { 2 - 3 } & $\begin{array}{c}\text { Pseudomonas floure- } \\
\text { scens }\end{array}$ & Aspergillus niger \\
\hline Kontrol & $6,009^{\mathrm{a}} \pm 0,199$ & $12,212^{\mathrm{a}} \pm 0,274$ \\
Oleoresin 2\% & $6,931^{\mathrm{b}} \pm 0,071$ & $14,425^{\mathrm{a}} \pm 2,652$ \\
Oleoresin 4 \% & $6,941^{\mathrm{b}} \pm 0,393$ & $15,431^{\mathrm{a}} \pm 1,043$ \\
Oleoresin 6\% & $7,094^{\mathrm{b}} \pm 0,079$ & $12,925^{\mathrm{a}} \pm 2,157$ \\
\hline
\end{tabular}

Keterangan: Notasi huruf yang sama pada kolom yang sama menunjukkan berbeda tidak nyata pada taraf signifikansi $5 \%$

\section{Konsentrasi Penambahan Oleoresin Ampas Sereh Dapur Terpilih}

Pemilihan konsentrasi penambahan oleoresin ampas sereh dapur terpilih dilakukan berdasarkan nilai yang diperoleh dari hasil pengujian tiap parameter. Kertas aktif dengan konsentrasi penambahan oleoresin ampas sereh dapur $2 \%$ memiliki nilai sensori yang lebih tinggi yang berarti lebih disukai oleh panelis pada parameter aroma dan overall dibandingkan $4 \%$ dan $6 \%$. Aktivitas antimikroba dan sifat fisikokimia kertas aktif dengan konsentrasi penambahan oleoresin ampas sereh dapur $2 \%$ berbeda tidak nyata dengan $4 \%$ dan $6 \%$. Sehingga konsentrasi penambahan oleoresin ampas sereh dapur $2 \%$ dipilih karena lebih efisien.

\section{Gugus Fungsi Kemasan Kertas Aktif Kontrol dan Konsentrasi $2 \%$}

Gambar 1 dan Tabel 4 menunjukkan gugus fungsi kitosan pada kemasan kertas aktif kontrol. Hasil karakterisasi gugus fungsi kitosan berdasarkan penelitian Fitriah dkk. (2012) yaitu panjang gelombang $3.448 \mathrm{~cm}^{-1}$ menunjukkan gugus $\mathrm{OH}$, panjang gelombang $1.658 \mathrm{~cm}^{-1}$ dan $902 \mathrm{~cm}^{-1}$ merupakan gugus $\mathrm{N}-\mathrm{H}$ yang menunjukkan gugus amina primer $\left(-\mathrm{NH}_{2}\right)$, senyawa $\mathrm{C}-\mathrm{H}$ ditunjukkan pada panjang gelombang 2.916 $\mathrm{cm}^{-1}$, dan untuk gugus $\mathrm{C}-\mathrm{O}$ muncul pada panjang gelombang $1.072 \mathrm{~cm}^{-1}$.

Menurut Fan dkk. (2012), gugus fungsi selulosa terdapat pada panjang gelombang $1.160 \mathrm{~cm}^{-1}, 1.316 \mathrm{~cm}^{-}$ , $1.370 \mathrm{~cm}^{-1}$, dan $1.424 \mathrm{~cm}^{-1}$. Diduga gugus fungsi dalam selulosa tersebut berturut-turut adalah $\left(\mathrm{C}-\mathrm{H}, \mathrm{C}-\mathrm{O}, \mathrm{CH}_{2}\right.$ dan $\mathrm{CH}_{3}$, dan $\mathrm{C}-\mathrm{C}$ ). Sedangkan gugus fungsi selulosa asetat menurut Gaol dkk. (2013) yaitu ditunjukkan pada panjang gelombang $3.400 \mathrm{~cm}^{-1}$ untuk $\mathrm{OH}, 2.950 \mathrm{~cm}^{-1}$ untuk $\mathrm{CH}_{3}$ asimetrik, $2.860 \mathrm{~cm}^{-1}$ untuk $\mathrm{CH}_{3}$ simetrik, dan $1.235 \mathrm{~cm}^{-1}$ untuk C-C-O asetat. Pada penelitian ini, pada kertas aktif kontrol gugus fungsi selulosa ditunjukkan pada panjang gelombang 3.168,22 $\mathrm{cm}^{-1}$ dan 3.299,38 $\mathrm{cm}^{-1}(\mathrm{O}-\mathrm{H}) ; 2.907,81$ $\mathrm{cm}^{-1}$ (C-H); 1.033,89 $\mathrm{cm}^{-1} ; 1.058,97 \mathrm{~cm}^{-1} ; 1.120,69 \mathrm{~cm}^{-1}$; $1.158,3 \mathrm{~cm}^{-1} ; 1.199,78 \mathrm{~cm}^{-1} ; 1.318,4 \mathrm{~cm}^{-1}$ (C-O); dan 1.427,39
Tabel 4. Gugus fungsi kemasan kertas aktif

\begin{tabular}{|c|c|c|}
\hline \multirow{2}{*}{ Gugus fungsi } & \multicolumn{2}{|c|}{ Panjang gelombang $\left(\mathrm{cm}^{-1}\right)$} \\
\hline & Kontrol & Konsentrasi $2 \%$ \\
\hline $\mathrm{O}-\mathrm{H}$ & $\begin{array}{l}3.168,22 \text { dan } \\
3.299,38\end{array}$ & $3.440,19$ \\
\hline $\mathrm{N}-\mathrm{H}$ & $1.659,82$ & $1.632,81$ \\
\hline C-H alkana & $2.907,81$ & $2.901,06$ \\
\hline $\mathrm{C}-\mathrm{O}$ & $\begin{array}{l}1.033,89 ; 1.058,97 ; \\
1.120,69 ; 1.158,3 ; \\
1.199,78 ; 1.318,4\end{array}$ & $\begin{array}{l}1.025,21 ; \\
1.059,93 ; 1.113,94 ; \\
1.167,95 ; 1.204,6 ; \\
1.318,4\end{array}$ \\
\hline $\mathrm{C}-\mathrm{N}$ & $\begin{array}{l}1.033,89 ; 1.058,97 ; \\
1.120,69 ; 1.158,3 ; \\
1.199,78\end{array}$ & $\begin{array}{l}1.025,21 ; 1.059,93 ; \\
1.113,94 ; 1.167,95 ; \\
1.204,6\end{array}$ \\
\hline $\mathrm{C}-\mathrm{C}$ & $1.427,39 ; 1.437,03$ & $1.433,17$ \\
\hline $\begin{array}{l}\text { C-H alkil } \\
\text { halida }\end{array}$ & $1.158,3 ; 1.199$ & $1.167,95 ; 1.204,6$ \\
\hline $\begin{array}{c}\mathrm{CH}_{2} \text { dan } \mathrm{CH}_{3} \\
\quad=\mathrm{C}-\mathrm{H}\end{array}$ & $\begin{array}{l}1.381,4 \\
708,87 ; 898,87 ; \\
992,42\end{array}$ & $\begin{array}{l}1.372,41 \\
666,43 ; 671,26 ; \\
702,12 ; 898,87 ; \\
984,7\end{array}$ \\
\hline $\mathrm{C}=\mathrm{O}$ & $1.720,58$ & $1.632,81$ \\
\hline $\mathrm{C}-\mathrm{Br}$ & $\begin{array}{l}569,03 ; 605,67 ; \\
666,43\end{array}$ & $\begin{array}{l}565,17 ; 624 ; 666,43 ; \\
671,26\end{array}$ \\
\hline $\mathrm{C}-\mathrm{Cl}$ & $\begin{array}{l}569,03 ; 605,67 ; \\
666,43 ; 708,87 ; \\
898,87\end{array}$ & $\begin{array}{l}565,17 ; 624 ; 666,43 ; \\
671,26 ; 702,12\end{array}$ \\
\hline
\end{tabular}

$\mathrm{cm}^{-1}$ serta $1.437,03 \mathrm{~cm}^{-1}$ (C-C). Sedangkan untuk kertas aktif dengan penambahan oleoresin sebanyak $2 \%$, gugus fungsi dari selulosa ditunjukkan pada panjang gelombang 3.440,19 $\mathrm{cm}^{-1}(\mathrm{O}-\mathrm{H}) ; 2.901,06 \mathrm{~cm}^{-1}(\mathrm{C}-\mathrm{H}) ; 1.025,21 \mathrm{~cm}^{-1} ; 1.059,93 \mathrm{~cm}^{-}$ ${ }^{1} ; 1.113,94 \mathrm{~cm}^{-1} ; 1.167,95 \mathrm{~cm}^{-1} ; 1.204,6 \mathrm{~cm}^{-1} ; 1.318,4 \mathrm{~cm}^{-1}$ (C-O); dan 1.433,17 $\mathrm{cm}^{-1}$ (C-C). Kertas aktif baik kontrol maupun penambahan oleoresin konsentrasi $2 \%$, mengandung gugus fungsi dari selulosa karena bahan baku dari kertas aktif ini merupakan kertas saring yang terbuat dari selulosa.

Menurut Ren dkk. (2012), rumus kimia tween 80 yaitu $\mathrm{C}_{7} \mathrm{H}_{14} \mathrm{CH}=\mathrm{CHC}_{8} \mathrm{H}_{17}$. Berdasarkan rumus kimia tersebut, tween 80 mengandung gugus fungsi $\mathrm{C}-\mathrm{H}\left(2.901,06 \mathrm{~cm}^{-1}\right)$, $\mathrm{CH}_{2}$ dan $\mathrm{CH}_{3}\left(1.372,41 \mathrm{~cm}^{-1}\right),=\mathrm{C}-\mathrm{H}\left(666,43 \mathrm{~cm}^{-1} ; 671,26 \mathrm{~cm}^{-}\right.$ 1; 702,12 $\left.\mathrm{cm}^{-1} ; 898,87 \mathrm{~cm}^{-1} ; 984,7 \mathrm{~cm}^{-1}\right)$, dan C-C $(1.433,17$ $\left.\mathrm{cm}^{-1}\right)$.

Kertas aktif dengan penambahan oleoresin $2 \%$ memiliki gugus fungsi dari senyawa aktif dalam oleoresin tersebut. Gugus fungsi oleoresin sereh dapur pada kemasan kertas aktif ditunjukkan dengan adanya gugus hidroksil (O$\mathrm{H})$ pada panjang gelombang $3.440,19 \mathrm{~cm}^{-1}$; gugus alkana $(\mathrm{C}$ - 


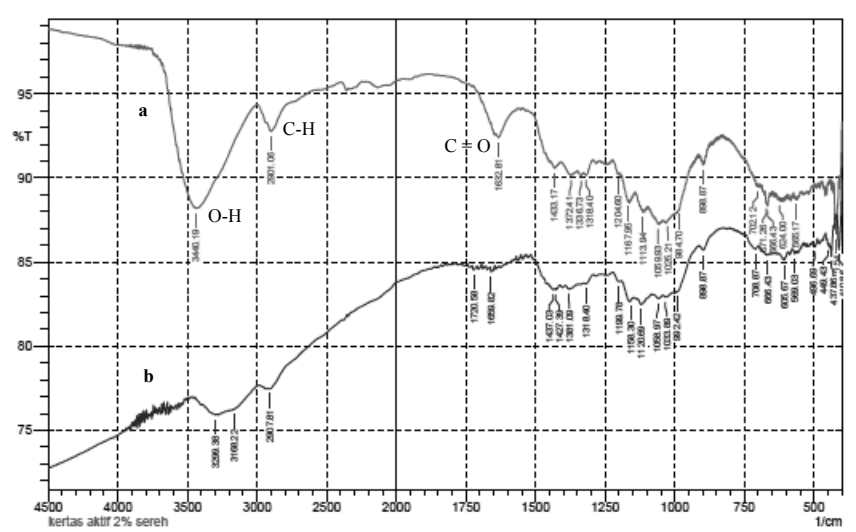

Keterangan:

a: Kertas aktif konsentrasi $2 \%$

b: Kertas aktif kontrol

Gambar 1. FT-IR Gugus Fungsi Kertas Aktif Kontrol dan Konsentrasi $2 \%$

H) pada panjang gelombang $2.901,06 \mathrm{~cm}^{-1}$; gugus karbonil $(\mathrm{C}=\mathrm{O})$ pada panjang gelombang $1.632,81 \mathrm{~cm}^{-1}$; gugus $\mathrm{C}-\mathrm{C}$ pada panjang gelombang $1.433,17 \mathrm{~cm}^{-1} ; \mathrm{CH}_{2}$ dan $\mathrm{CH}_{3}$ pada panjang gelombang $1.372,41 \mathrm{~cm}^{-1}$; dan $=\mathrm{C}-\mathrm{H}$ pada panjang gelombang $666,43 \mathrm{~cm}^{-1}, 671,26 \mathrm{~cm}^{-1}, 702,12 \mathrm{~cm}^{-1}, 898,87$ $\mathrm{cm}^{-1}$, serta $984,7 \mathrm{~cm}^{-1}$. Sedangkan dalam penelitian Ain dkk. (2013), oleoresin sereh dapur mengandung gugus hidroksil (O-H) pada panjang gelombang $3.400 \mathrm{~cm}^{-1}$, gugus alkana (CH) pada panjang gelombang $2.913 \mathrm{~cm}^{-1}$ dan $2.849 \mathrm{~cm}^{-1}$ serta terdapat juga pada panjang gelombang $1.463 \mathrm{~cm}^{-1}$, dan gugus karbonil $(\mathrm{C}=\mathrm{O})$ pada panjang gelombang $1.738 \mathrm{~cm}^{-1}$.

Berdasarkan Gambar 1, terlihat bahwa antara kemasan kertas aktif kontrol dan konsentrasi $2 \%$ memiliki pola spektrum yang hampir sama. Gugus fungsi yang terkandung dalam kedua kertas tersebut juga sama. Namun pada kemasan kertas aktif konsentrasi $2 \%$ memiliki peak yang lebih tajam dibandingkan kertas aktif kontrol yaitu pada panjang gelombang $3.440,19 \mathrm{~cm}^{-1} ; 2.901,06 \mathrm{~cm}^{-1}$; dan $1.632,81$ $\mathrm{cm}^{-1}$ yang menunjukkan gugus fungsi $\mathrm{O}-\mathrm{H}, \mathrm{C}-\mathrm{H}$, dan $\mathrm{C}=\mathrm{O}$.
Ketajaman peak pada kertas konsentrasi $2 \%$ menunjukkan bahwa kertas aktif konsentrasi $2 \%$ mengandung gugus fungsi $\mathrm{O}-\mathrm{H}, \mathrm{C}-\mathrm{H}$, dan $\mathrm{C}=\mathrm{O}$ lebih banyak dibandingkan kertas aktif kontrol. Hal ini dikarenakan dalam kertas aktif konsentrasi 2 $\%$ ditambahkan tween 80 dan oleoresin ampas destilasi sereh dapur yang mengandung gugus tersebut.

\section{Karakteristik Fisik Kemasan Kertas Aktif Selama Penyimpanan}

Pada Tabel 5, ketahanan tarik kemasan kertas aktif kontrol pada hari ke-5, 15, dan 20 tidak berbeda nyata dengan kemasan kertas aktif kontrol pada hari ke-0 dan 10, namun kemasan kertas aktif kontrol pada hari ke-0 berbeda nyata dengan kemasan kertas aktif kontrol pada hari ke-10. Sedangkan pada kemasan kertas aktif konsentrasi $2 \%$ memiliki nilai yang berbeda nyata pada hari ke- 0,5 , dan 20 dengan hari ke-10 dan 15. Namun baik kemasan kertas aktif kontrol maupun kertas dengan penambahan oleoresin $2 \%$ memiliki pola yang sama yaitu dari hari ke-0 mengalami peningkatan pada hari ke-5 dan hari ke-10 kemudian turun di hari ke-15 dan 20. Menurut Caulfied dan Gunderson (1988), lama waktu penyimpanan tidak mempengaruhi nilai ketahanan tarik kertas. Faktor yang mempengaruhi ketahanan tarik adalah kenaikan suhu dan kondisi kelembaban lingkungan yang menyebabkan perubahan kimia pada kertas sehingga dapat menurunkan tingkat kekuatan tariknya. Perlakuan suhu yang lebih tinggi, misalnya pada proses pengeringan, maupun laju pengeringan yang tinggi mengakibatkan struktur film menjadi padat dan lebih berpori karena tidak tersedia cukup waktu bagi jaringan polimer untuk merapat (Alyanak dkk., 2004; Tapia-Blácido dkk., 2005). Alyanak dkk. (2004) menjelaskan bahwa struktur yang lebih berpori dapat mengakibatkan ketahanan tarik film lebih rendah.

Antara kemasan kertas aktif kontrol dengan kemasan kertas aktif penambahan oleoresin konsentrasi $2 \%$ berbeda nyata di setiap 5 hari penyimpanan. Hal ini menunjukkan bahwa penambahan tween 80 dalam kemasan kertas aktif

Tabel 5. Nilai ketahanan tarik dan ketahanan lipat kemasan kertas aktif selama penyimpanan

\begin{tabular}{ccccc}
\hline \multirow{2}{*}{ Penyimpanan hari ke- } & \multicolumn{2}{c}{ Ketahanan tarik (N/mm) } & \multicolumn{2}{c}{ Ketahanan lipat } \\
\cline { 2 - 5 } & Kontrol & Konsentrasi $2 \%$ & Kontrol & Konsentrasi $2 \%$ \\
\hline 0 & $1,508^{\mathrm{A}} \mathrm{b} \pm 0,139$ & $0,725^{\mathrm{A}} \mathrm{a} \pm 0,093$ & $1,040^{\mathrm{A}} \mathrm{a} \pm 0,056$ & $0,540^{\mathrm{A}} \mathrm{a} \pm 0,088$ \\
5 & $1,591^{\mathrm{AB}} \mathrm{b} \pm 0,086$ & $0,926^{\mathrm{A}} \mathrm{a} \pm 0,029$ & $1,113^{\mathrm{A}} \mathrm{a} \pm 0,047$ & $0,900^{\mathrm{B}} \mathrm{a} \pm 0,077$ \\
10 & $1,898^{\mathrm{B}} \mathrm{b} \pm 0,197$ & $1,277^{\mathrm{B}} \mathrm{a} \pm 0,141$ & $1,620^{\mathrm{B}} \mathrm{a} \pm 0,244$ & $1,263^{\mathrm{C}} \mathrm{a} \pm 0,083$ \\
15 & $1,675^{\mathrm{AB}} \mathrm{b} \pm 0,049$ & $1,236^{\mathrm{B}} \mathrm{a} \pm 0,066$ & $1,617^{\mathrm{B}} \mathrm{a} \pm 0,103$ & $1,256^{\mathrm{C}} \mathrm{a} \pm 0,201$ \\
20 & $1,673^{\mathrm{AB}} \mathrm{b} \pm 0,018$ & $0,935^{\mathrm{A}} \mathrm{a} \pm 0,069$ & $1,109^{\mathrm{A}} \mathrm{a} \pm 0,095$ & $0,866^{\mathrm{B}} \mathrm{a} \pm 0,124$ \\
\hline
\end{tabular}

Keterangan:

Notasi huruf besar yang sama pada kolom yang sama menunjukkan berbeda tidak nyata pada taraf signifikansi $5 \%$, notasi huruf kecil yang sama pada baris yang sama menunjukkan berbeda tidak nyata pada taraf signifikansi $5 \%$ 
Tabel 6. Hasil pengujian aktivitas antimikroba kemasan kertas aktif

\begin{tabular}{lcccc}
\hline & \multicolumn{3}{c}{ Diameter zona bening $(\mathrm{mm})$} \\
\cline { 2 - 5 } Kertas aktif & Sebelum penyimpanan & Setelah penyimpanan & \multicolumn{2}{c}{ Aspergillus niger } \\
\hline Kontrol & & $(20$ hari) & Sebelum penyimpanan & Setelah penyimpanan \\
Konsentrasi $2 \%$ & $6,010^{\mathrm{A}} \mathrm{a} \pm 0,20$ & $5,837^{\mathrm{A}} \mathrm{a} \pm 0,04$ & $12,212^{\mathrm{A}} \mathrm{a} \pm 0.27$ & $10,086^{\mathrm{A}} \mathrm{a} \pm 1,14$ \\
\hline
\end{tabular}

Keterangan:

Notasi huruf besar yang sama pada kolom yang sama menunjukkan berbeda tidak nyata pada taraf signifikansi $5 \%$, notasi huruf kecil yang sama pada baris yang sama menunjukkan berbeda tidak nyata pada taraf signifikansi $5 \%$

mempengaruhi ketahanan tarik kemasan kertas aktif selama penyimpanan. Kertas dengan penambahan oleoresin $2 \%$ mengandung tween 80 yang dapat membuat kertas bersifat porous sehingga lebih rapuh. Selain itu, tween 80 juga membuat kertas bersifat higroskopis sehingga kandungan air dalam kertas lebih tinggi dan juga membuat kertas lebih rapuh. Tween 80 mempunyai banyak gugus hidroksil $(\mathrm{OH})$ yang dapat mengikat air (Kamsiati, 2006). Kertas yang lebih rapuh akan membuat nilai ketahanan tariknya semakin kecil.

Pada Tabel 5, ketahanan lipat kemasan kertas aktif kontrol penyimpanan hari ke-0, 5, dan 20 berbeda nyata dengan penyimpanan hari ke-10 dan 15 . Sedangkan pada kemasan kertas aktif konsentrasi $2 \%$ hari ke-0 berbeda nyata dengan hari ke-5 dan 20 serta berbeda nyata dengan hari ke-15 dan 20. Namun baik kemasan kertas aktif kontrol maupun kertas dengan penambahan oleoresin $2 \%$ memiliki pola yang sama yaitu dari hari ke-0 mengalami peningkatan pada hari ke-5 dan hari ke-10 kemudian turun di hari ke-15 dan 20. Menurut Caulfied dan Gunderson (1988), selama penyimpanan nilai ketahanan lipat lebih mudah mengalami perubahan dibanding ketahanan tarik. Selama penyimpanan ketahanan lipat semakin menurun karena adanya degradasi kertas yang menyebabkan melemahnya serat-serat dalam kertas.

Kemasan kertas aktif kontrol dengan kemasan kertas aktif penambahan oleoresin konsentrasi $2 \%$ memiliki nilai ketahanan lipat yang berbeda tidak nyata selama penyimpanan. Ketahanan lipat kemasan kertas aktif dalam penelitian ini berskisar antara 0,540-1,620.

\section{Aktivitas Antimikroba Setelah Penyimpanan}

Kemasan kertas aktif kontrol dengan konsentrasi $2 \%$ berbeda tidak nyata dalam penghambatan Pseudomonas fluorescens dan Aspergillus niger baik sebelum maupun setelah penyimpanan (Tabel 6). Setelah 20 hari penyimpanan, kemasan kertas aktif konsentrasi $2 \%$ dan kontrol memiliki daya hambat sedang terhadap bakteri Pseudomonas fluorescens dan memiliki daya hambat kuat terhadap jamur Aspergillus niger.

\section{KESIMPULAN}

Konsentrasi oleoresin berpengaruh nyata terhadap warna, overall, ketahanan tarik, ketahanan lipat dan aktivitas antimikroba tetapi berpengaruh tidak nyata terhadap aroma, tekstur, kadar air, dan ketebalan kemasan kertas aktif. Penambahan oleoresin ampas destilasi sereh dapur meningkatkan kadar air, ketebalan, dan aktivitas antimikroba serta menurunkan ketahanan tarik, ketahanan lipat, dan penerimaan panelis. Kemasan kertas aktif mengandung gugus fungsi selulosa, kitosan, dan tween 80 serta pada kemasan kertas aktif penambahan oleoresin konsentrasi $2 \%$ terdapat gugus fungsi oleoresin sereh dapur. Waktu penyimpanan berpengaruh tidak nyata terhadap ketahanan tarik dan ketahanan lipat kemasan kertas aktif kontrol dan konsentrasi terpilih. Kemasan kertas aktif kontrol dengan kemasan kertas aktif penambahan oleoresin konsentrasi $2 \%$ berbeda nyata di setiap 5 hari penyimpanan. Penyimpanan selama 20 hari berpengaruh tidak nyata terhadap aktivitas antimikroba kemasan kertas aktif kontrol dan konsentrasi terpilih.

\section{UCAPAN TERIMA KASIH}

Terima kasih kepada Direktorat Jendral DIKTI atas pembiayaan melalui skema Hibah Penelitian Unggulan Perguruan Tinggi Tahun Anggaran 2015 (No 339/UN27.11/ PL/2015).

\section{DAFTAR PUSTAKA}

Ain, N., Zaibunnisa, Zahrah, H. dan Norashikin. (2013). An experimental design approach for the extraction of lemongrass (Cymbopogon citratus) oleoresin using Pressurised Liquid Extraction (PLE). International Food Research Journal 20(1): 451-455.

Alyanak, D. (2004). Water Vapour Permeable Edible Membranes. Tesis. Biotechnology and Bioengineering 
Program. Izmir Institute of Technology.

Amaliya, R.R. dan Putri, W.D.R. (2014). Karakteristik edible film dari pati jagung dengan penambahan filtrat kunyit putih sebagai antibakteri. Jurnal Pangan dan Agroindustri. 2(3): 43-53.

Caulfield, D.F. dan Gunderson (1988). Paper Testing and Strength Characteristics. Technical Association for the Pulp and Paper Industry Press. Washington DC.

Chasanah, E., Fawzya, Y.N., Ariani, F. dan Maruli (2013). Bioaktivitas kitooligosakarida yang diproduksi dari kitosan menggunakan kitosanase microminospora T5a1 sebagai antikapang. Jurnal Pascapanen dan Bioteknologi Kelautan dan Perikanan 8(1): 65-72.

Danlami, U., Rebecca, A., Machan, D.B. dan Asuquo, T.S. (2011). Comparative study on the antimicrobial activities of the ethanolic extract of Lemongrass and Polyalthia longifolia. Journal of Applied Pharmaceutical Science 01(09): 174-176.

Dobrucka, R. dan Cierpiszewski, R. (2014). Active and intelligent packaging food-research and development-a review. Polish Journal Food Nutrition Sciences 64(1): 7-15.

Elifah, E. (2010). Uji Antibakteri Fraksi Aktif Ekstrak Metanol Daun Senggani (Melastoma candidum, D.Don) terhadap Escherichia coli dan Bacillus subtilis Serta Profil Kromatografi Lapis Tipisnya. Skripsi. Fakultas Matematika dan Ilmu Pengetahuan Alam. Universitas Sebelas Maret (UNS), Surakarta.

Ella, M.U., Sumiartha, K., Suniti, N.W., Sudiarta, I.P. dan Antara, N.S. (2013). Uji efektivitas konsentrasi minyak atsiri sereh dapur (Cymbopogon citratus (DC.) Stapf) terhadap pertumbuhan jamur Aspergillus Sp. secara in vitro. E-Jurnal Agroteknologi Tropika 2(1): 39-48.

Fan, M.D.D. dan Huang, B. (2012). Fourier TransformMaterial Analysis. Intech China.

Fauzi, I. (2006). Evaluasi Permeansi Uap Air pada Kemasan Fleksibel dan Metode Penentuan Umur Simpan Wafer Stick di PT Arnott's Indonesia, Bekasi. Skripsi. Fakultas Teknologi Pertanian. Institut Pertanian Bogor, Bogor.

Fitriah, H., Mahatmanti, F.W. dan Wahyuni, S. (2012). Pengaruh konsentrasi pada pembuatan membran kitosan terhadap selektivitas ion Zn (II) dan Fe (II). Indonesian Journal of Chemical Science 1(2): 104-109.

Fitriani, E., Alwi, M. dan Umrah. (2013). Studi efektivitas ekstrak daun sereh wangi (Cymbopogon nardus L.) sebagai anti fungi Candida albicans. Biocelebes 7(2):15-20.

Gaol, M.R.L.L., Sitorus, R., Yanthi, S., Surya, I. dan
Manurung, R. (2013). Pembuatan selulosa asetat dari $\alpha$-selulosa tandan kosong kelapa sawit. Jurnal Teknik Kimia. 2(3): 33-39.

Hadi, M. (2008). Pembuatan kertas anti rayap ramah lingkungan dengan memanfaatkan ekstrak daun kirinyuh. BIOMA 6(2): 12-18.

Kamsiati, E. (2006). Pembuatan bubuk sari buah tomat (Licopersicon esculentum Mill.) dengan metode "foammat drying”. Jurnal Teknologi Pertanian 7(2): 113-119.

Kawiji, Khasanah, L.U. dan Pramani, C.A. (2010). Pengaruh perlakuan awal bahan baku dan waktu destilasi serai dapur (Cymbopogon citratus) terhadap karakteristik fisikokimia minyak serai dapur (Lemongrass oil). Jurnal Teknologi Hasil Pertanian 1(1): 59-71.

Khasanah, L.U., Kawiji, Utami, R., Anandito, B.A. dan Achmad, F. (2013). Karakterisasi oleoresin ampas destilasi minyak atsiri daun jeruk purut (Citrus hystrix DC), hal. 404-408. Prosiding Seminar Nasional Agribisnis.

Killay, A. (2013), Kitosan sebagai anti bakteri pada bahan pangan yang aman dan tidak berbahaya (review), hal. 200-205. Prosiding FMIPA Universitas Pattimura.

Kurniasih, M. dan Kartika, D. (2011). Sintesis dan karakterisasi fisika-kimia kitosan. Jurnal Inovasi 5 (1): 42-48.

Kusumayadi, Hendra, I.W., Sukewijaya, I.M., Sumiartha, I.K. dan Antara, N.S. (2013). Pengaruh ketinggian tempat. mulsa dan jumlah bibit terhadap pertumbuhan dan rendemen minyak sereh dapur (Cymbopogon citratus). E-Jurnal Agroteknologi Tropika 2(1): 49-55.

Manuhara, G.J. (2013). Pengaruh Suhu dan Lama Waktu Penyimpanan terhadap Aktivitas Antimikroba, Sifat Kimia dan Fisik Kertas Aktif yang Mengandung Sinamaldehid. Tesis. Universitas Gadjah Mada, Yogyakarta.

Matasyoh, J.C., Wagara, I.N., Nakavuma, J.L. dan Kiburai, A.M. (2011). Chemical composition of cymbopogon citratus oil and its effect on mycotoxigenic Aspergillus niger. African Journal of Food Science 5(3): 138-142.

Nurainy, F., Rizal, S. dan Yudiantoro (2008). Pengaruh konsentrasi kitosan terhadap aktifitas antibakteri dengan metode difusi agar (sumur). Jurnal Teknologi Industri dan Hasil Pertanian 13(2): 117-125.

Pebriani, R.H., Rilda, Y. dan Zulhadjri (2012), Modifikasi komposisi kitosan pada proses sintesis komposit $\mathrm{TiO}_{2}$ Kitosan. Jurnal Kimia 1(1): 40-47.

Prasetyo, S. dan Vincentius (2005). Pengaruh penambahan 
tween 80 , dekstrin, dan minyak kelapa pada pembuatan kopi instan menggunakan metode pengering biasa. Jurnal Teknik Kimia Indonesia 4(3): 296-303.

Rahman, H., Husain, D.R., dan Abdullah, A. (2013). Bioaktifitas Minyak Atsiri Sereh Cymbopogon citratus DC. terhadap Pertumbuhan Bakteri Escherichia coli dan Staphylococcus aureus. Skripsi. Jurusan Biologi. Fakultas Matematika dan Ilmu Pengetahuan Alam. Universitas Hasanuddin, Makasar.

Ren, W., Tian, G., Jian, S., Gu, Z., Zhou, L., Yan, L., Jin, S., Yin, W. dan Zhao, Y. (2012). Tween coated $\mathrm{NaYF}_{4}: \mathrm{Yb}, \mathrm{Er} /$ $\mathrm{NaYF}_{4}$ core/shell upconversion nanoparticles for bioimaging and drug delivery. Electric Supplementary Material (ESI) for RSC Advances. China.

Rodriguez, A., Nerin, C. dan Batlle, R. (2008). New Cinnamonbased active paper packaging against rhizopus stolonifer food spoilage. Journal of Agricultural and Food Chemistry. 56: 6364-6369.

Sucipto, Wijana, S. dan Wahyuningtyas, E. (2009). Optimasi penggunaan $\mathrm{NaOH}$ dan tapioka pada produksi kertas seni dari pelepah pisang. Jurnal Teknologi Pertanian 10 (1): 46-53.
Tapia-Blácido, D., Sobral, P.J. dan Menegalli. (2005). Effects of drying temperature and relative humidity on the mechanical properties of amaranth flour films plasticized with glycerol. Brazilian Journal of Chemical Engineering 22(02): 249-256.

Tongnuanchan, P., Benjakul, S. dan Prodpran, T. (2014). Comparative studies on properties and antioxidative activity of fish skin gelatin films incorporated with essential oils from various sources. Journal International Aquatic Research 6(62): 1-12.

Utami, R., Nurhartadi, E. dan Putra, A.Y.T. (2013). Pengaruh penambahan minyak atsiri kunyit putih (Kaempferia rotunda) pada edible film pati tapioka terhadap aktivitas antimikroba dan sensoris. Jurnal Teknosains Pangan 2(2): 51-56. 